\title{
Expression of the Bradyrhizobium japonicum Type III Secretion System in Legume Nodules and Analysis of the Associated tts box Promoter
}

\author{
Susanne Zehner, Grit Schober, Mandy Wenzel, Kathrin Lang, and Michael Göttfert \\ Institute of Genetics, Dresden University of Technology, Helmholtzstrasse 10, D-01062 Dresden, Germany \\ Submitted 25 February 2008. Accepted 8 April 2008.
}

\begin{abstract}
In Bradyrhizobium japonicum, as in some other rhizobia, symbiotic efficiency is influenced by a type III secretion system (T3SS). Most genes encoding the transport machinery and secreted proteins are preceded by a conserved 30bp motif, the type-three secretion (tts) box. In this study, we found that regions downstream of $34 \mathrm{tts}$ boxes are transcribed. For nopB, nopL, and gunA2, the transcriptional start sites were found to be 12, 11, and 10 bp downstream of their $t$ s boxes, respectively. The deletion of this motif or modification of two or more conserved residues strongly reduced expression of nopB. This indicates that the tts box is an essential promoter element. Data obtained with lacZ reporter gene fusions of five genes preceded by a tts box (gunA2, nopB, rhcV, nopL, and blr1806) revealed that they are expressed in 4-week-old nodules of Macroptilium atropurpureum. These data suggest that the T3SS is active in mature nitrogen-fixing nodules. The two-component response regulator TtsI is required for the expression of rhcV, nopL, and blr1806 in bacteroids. Staining of inoculated roots showed that nopB is also expressed in early infection stages.
\end{abstract}

The symbiotic interaction between rhizobia and legumes is initiated by a highly specific recognition of the two partners (Broughton et al. 2000). Plant flavonoids induce the expression of nod genes in rhizobia. The Nod proteins are responsible for the biosynthesis of lipo-chito-oligosaccharides, the Nod factors. These compounds trigger the formation of root nodules by the host plants (Long 2001; Spaink 2000). Flavonoids also induce the expression of a type III secretion system (T3SS), which is present in several rhizobia (Marie et al. 2001). Depending on the host plant, the T3SS can be detrimental or beneficial for symbiosis or may have no obvious influence (Marie et al. 2001; Viprey et al. 1998). In Bradyrhizobium japonicum, a type III secretion mutant forms fewer nodules on Macroptilium atropurpureum than the wild type and has a delayed nodulation phenotype on soybean. The mutation does not strongly influence the interaction with cowpea (Krause et al. 2002). Genes that probably encode core components of the secretion apparatus (rhizobia-conserved proteins [Rhc]) are clustered. This type-three secretion (tts) gene cluster also encodes secreted proteins (e.g., nodulation outer proteins NopB and NopL). $n o p B$ is conserved in all rhizobia encoding a T3SS. It is the first gene of a highly conserved operon containing several $r h c$

Corresponding author: S. Zehner; Telephone: +49-351-46335407; Fax: +49-351-46337725; E-mail: susanne.zehner@tu-dresden.de genes. NopB was found to be secreted by Sinorhizobium fredii USDA 257 and Rhizobium sp. strain NGR234, and it is associated with extracellular structures of the secretion apparatus (Lorio et al. 2004; Saad et al. 2005). nopL is present in NGR234, S. fredii, and B. japonicum (Göttfert et al. 2001; Krishnan et al. 2003; Viprey et al. 1998). NopL probably acts as an effector protein in plants (Bartsev et al. 2003; Marie et al. 2003). In B. japonicum, type III-secreted proteins are also encoded outside of the $t$ ts gene cluster. An example is GunA2 (Süß et al. 2006), which exhibits cellulase activity in vitro (Caldelari Baumberger et al. 2003).

One of the conserved genes in the tts cluster is $t t s I$. The deduced protein has high similarity to regulators belonging to the two-component regulatory systems. It is essential for induction of other genes in this cluster and for type III secretion (Krause et al. 2002; Marie et al. 2004; Süß et al. 2006). Upstream of TtsI-regulated genes, a conserved $t t s$ box motif was identified (Krause et al. 2002; Marie et al. 2004). We were interested in the role of the $t t s$ box for expression of the downstream genes. Here, we give experimental evidence that the $t t s$ box is an essential promoter element. Our data also suggest that the T3SS is expressed at early stages of plant infection and in mature nodules.

\section{RESULTS}

Distribution and transcription

of $t$ ts box regions in the $B$. japonicum genome.

A genome survey revealed 39 conserved $t t s$ box motifs in $B$. japonicum (Süß et al. 2006) (Fig. 1). The tts box-like sequences were found upstream of i) $r h c$ and nop genes, ii) genes that encode proteins with similarity to virulence factors, iii) a flgBlike gene, and iv) genes encoding proteins of hypothetical or unknown functions. Seven tts box motifs were found in regions without annotated genes in close vicinity. Most $t t s$ boxes $(n=$ 31 ) are located in the symbiotic gene region of the B. japonicum genome. To examine the expression of downstream regions, reverse-transcription polymerase chain reaction (PCR) was applied. RNA was isolated from the wild-type strain grown in arabinose gluconate salts (AG) medium supplemented with genistein (discussed below). Primers were selected to amplify fragments located 20 to $250 \mathrm{bp}$ downstream of the predicted $t t s$ boxes. For three regions (upstream of bll1798, bll1848, and bll8244), PCR with two different primer pairs failed to amplify fragments from cDNA and also from chromosomal DNA. In 34 cases, PCR fragments were obtained with cDNA templates, indicating transcriptional activity. Two genomic regions downstream of tts box-like motifs (9101960f and 1798864r) do not seem to be transcribed. 
The $t$ ts box is an essential promoter element of $t$ ts genes.

To find out whether the tts box was located within the promoter region, the transcriptional start sites of nopB, nopL, and gunA2 were determined by $5^{\prime}$ rapid amplification of cDNA ends (RACE). This revealed that transcription starts 10 (gunA2), 11 (nopL), or 12 (nopB) nucleotides downstream of the assigned tts box motifs (Fig. 2). To determine whether all three highly conserved regions (Fig. 1) are required for promoter activity, the corresponding regions upstream of a nopB-lac $Z$ fusion were modified (Table 1). The promotor region of $n o p B$ was selected, because $n o p B$ is the first gene of an operon encoding several conserved components of the T3SS. The variants as
Downstream

gene

$\mathrm{b} \ln 1649$

bs 11652

gunA2

blr 1676

blr1704

nopP

blr 1787

bl11798

bl1 $1804^{2}$

blr1806

bs 11808

nopL

nopB

bsr1831

bll1840

bl1 1848

blr1854

bl11862a

bl11862b

blr1869

bl1 1877

blr1904

pgl

blr2052

blr2058

blr2140

bsr3674

blr4 695

flgB

blr7131

bl1 8201

bl18244

$1798864 r$

$1806041 r$

$2000571 r$

$2154581 \mathrm{f}$

$2220599 r$

$6329127 \mathrm{f}$

$9101960 \mathrm{f}$

consensus

$$
-35
$$$$
-24
$$$$
-11
$$

TTGTCGTCAGCTTTTCGACAGGTGCTGCAGGTAGAGTC TCTTAGTCAGCTTTTCGCAAGCTGCTCCTGCTAGCATG AGCTCGTCAGCTTCTCGAAAGCCAACCTTCCTAGCATT CGCTCGTCAGCTCGACGTAAGCTAAATGTCTTAGAGGC CCTACGTCAGCTACTCGTCAGCCAGCCAGTCTATGCAG CTTAGGTCAGGTTGTGGTCAGTTAGGTTGTATATTATG ACTGCGTCAGGTTATCGACAGGTGGCGCTCGTATCATG TTAGCGTCAGCTTGCCGACAGCTAGGCTTACTATGAGC GGCTCGTCAGCTTTTCGAAAGCTAGCGCCCCTAGCATG TCATCGTCAGCTTTTCGACAGGTGTTCGGGCTACCGTA TCTTCGTCAGCTTCTTGCAAGCTGCCCCTGCTAGCACG CGATCGTCAGCTTTCGAAAGCTAAAGCCCCCAGCATG TCTCCGTCAGGTTTTCGTCAGCTCGGCAGCCTATGAAC GTCTCGTCAGCTTTCAGTAAGCCAGCCCGGATACAGAG GCGATGTCAGGTTTTGGAAAGAAACGTGAGTAGCGAA GGTCTGTCAGCTGTTCGACAGCTAGGCTTTCTAGCATA TCTTGGTCAGCTAGTCGTCAGCCAGTCGGCCTATCCAG GCTTTGTCAGCTTTCTGTCAGCTCGTCCAAATAGTAGC TCGGCGTCAGCTTACGGACAGCTAAGCTGCTTATCTGC CCTTTGTCAGCTTCTCGAAAGCCAGCCTCTCTAACACT AGCACGTCAGCTTGTCGACAGCTGATCCTAATAGAGTG CATTCGTCAGCTTATCGACAGGTAGGCCTGCTAAGGGC GCCTCGTCAGCTTCTCGAAAGCTTTCCCGAATACTCAC GCTTCGTCAGCTTCTCGAAAGCTAGCTTTCACATAACG TGGTGGCCAGCTCCTCGTCAGTTTGCCGCGATATCGGT TGTCCGTCAGCTCGCCATCAGCTTGTCCGGGTATCCTC CTTTGGTCAGGTTCACGACATCTCCTTTCGAGAACAGA GGTCTGTCAGCTTCGCGTCAGGTAAGCCTTCGAGATCG CGCCCAACAGCTTGACGAAAGCTTAACGCCCTAGGCTT TTGAAGTCAGTTTGTCGTGAGTTGTCCCGGGTAGCGCT GCTTTGTCAGCTTTCTGTCAGCTCGTCCAAATAGTAGC TCGTCATCAGGTTCTCGACAGCTTCCCCATTTAAGTTT GTCTCGTCAGCTTTCAGTAAGCTAGTCCCAATAATTGG GACTCGTCAGCTTCTCGAAAGGTAGCGCGCCTAGCGTG ATCTCGTCAGCTTCTCGAAAGCTGCGCCTGCAAACAAT ATCTCGTCAGCTTCTTGAAAGGTTGCGGCTACAACAAT GGTTCGTCAGCTTTTGGACAGCTATTCGGTGTACAATG GGCTTGTCAGGCTGTCGTAAGCTCAGCCCGCTAGGGTC TCTTTGTCAGCTTTTGGAAAGCTAGCCCGAATACTCAG

Characteristics of encoded proteins

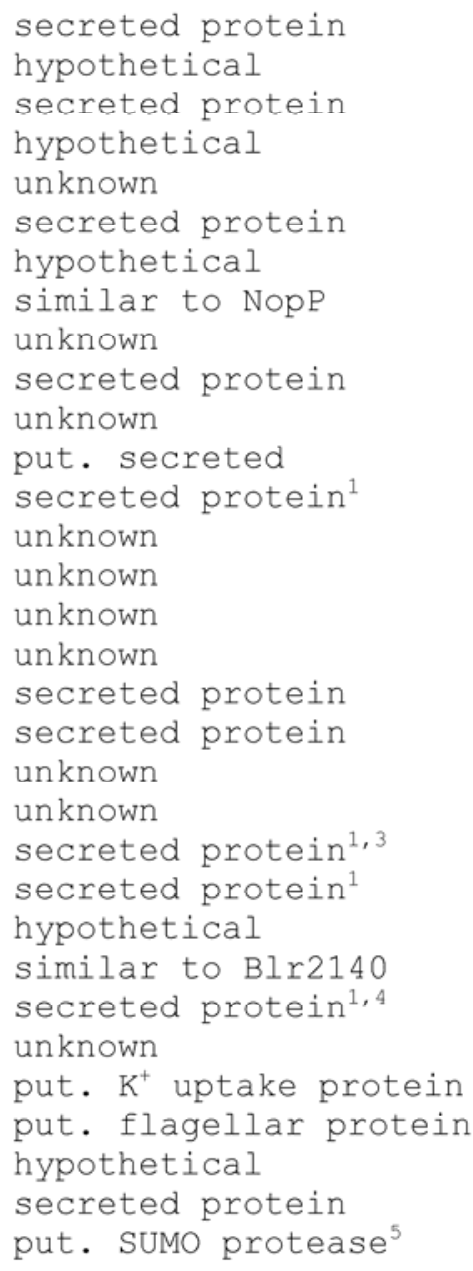

1 unpublished results, this lab

2 rhcV is located downstream in the same operon

3 similar to proteins of the IpaH family of Shigella flexneri

4 YopT-like protein, put. protease

5 XopD-like protein

Fig. 1. Type-three secretion (tts) box motifs in the genome of Bradyrhizobium japonicum. Sequence analysis was performed as described (Süß et al. 2006). The tts boxes without downstream annotated genes are referred to by their position in the genome (accession NC_004463). Highly conserved nucleotide positions $(\geq 90 \%)$ are shown in bold letters. In the consensus sequence, lowercase letters are used for nucleotides conserved in at least $50 \%$ of the sequences; $\mathrm{n}$ means any nucleotide. Conserved regions in the consensus are underlined.

1088 / Molecular Plant-Microbe Interactions 
well as the $n o p B-l a c Z$ fusion preceded by the wild-type motif were integrated into the chromosome of $B$. japonicum (Tables 1 and 2) and $\beta$-galactosidase activity was measured (Fig. 3). With the wild-type tts box, $\beta$-galactosidase activity was inducible by genistein. If the $t$ ts box was deleted (strain BJD322), $\beta$ galactosidase activity dropped to background level. Transcriptional activity was also strongly impaired if two conserved nucleotides of region 1, 2, or 3 were modified (strains BJD328, BJD327, and BJD326, respectively) or if three nucleotides of region 1 were deleted (BJD324). Reporter activity was not inducible by genistein in any of the mutants. In strains BJD323 and BJD325, the distances between the conserved regions of the $t t s$ box were changed. In both strains, the nopB-lacZ fusion was still inducible, albeit at a low level. A substitution of just one conserved nucleotide in region 1 (BJD329) reduced reporter

Table 1. Generated type-three secretion (tts) box modifications

\begin{tabular}{|c|c|c|c|}
\hline \multirow[b]{2}{*}{ Strain } & \multicolumn{3}{|c|}{ tts Box motif/mutation ${ }^{\text {a }}$} \\
\hline & Region 1 & Region 2 & Region 3 \\
\hline BJD321 & \multicolumn{3}{|c|}{ TCCGTCAGGTTTTCGTCAGCTCGGCAGCCTATGAAC } \\
\hline BJD322 & \multicolumn{3}{|c|}{ TCC . . . . . . . . . . . . . TGAAC } \\
\hline BJD323 & \multicolumn{3}{|c|}{ TCCGTCAGGTTTTCGTCAGCTCGG . . CCTATGCAC } \\
\hline BJD324 & \multicolumn{3}{|c|}{ TCCGT... GTTTTCGTCAGCTCGGCAGCCTATGAAC } \\
\hline BJD325 & \multicolumn{3}{|c|}{ TCCGTCAGGTTGAGTTCGTCAGCTCGGCAGCCTATG } \\
\hline BJD326 & \multicolumn{3}{|c|}{ TCCGTCAGGTTTTCGTCAGCTCGGCAGCCATTGAAC } \\
\hline BJD327 & \multicolumn{3}{|c|}{ TCCGTCAGGTTTTCGTCGACTCGGCAGCCTATGAAC } \\
\hline BJD328 & \multicolumn{3}{|c|}{ TCCACCAGGTTTTCGTCAGCTCGGCAGCCTATGAAC } \\
\hline BJD329 & \multicolumn{3}{|c|}{ TCCGTAAGGTTTTCGTCAGCTCGGCAGCCTATGAAC } \\
\hline BJD330 & \multicolumn{3}{|c|}{ TCCGTCAGATTTTCGACAGCTAGGCAGCCTATGAAC } \\
\hline Consensus $^{\mathrm{b}}$ & \multicolumn{3}{|c|}{ ntcGTCAGCTtntCGaCAGctagncnnnctAnnnnn } \\
\hline
\end{tabular}

${ }^{a}$ Nucleotide substitutions are in bold italics and nucleotide deletions are indicated by dots.

${ }^{\mathrm{b}}$ Highly conserved nucleotides $(\geq 90 \%)$ are in bold, lowercase characters are used for conserved nucleotides ( $\geq 50 \%)$, and $\mathrm{n}=$ any nucleotide activity only slightly. A similar result was obtained for strain BJD330, in which three modifications were introduced, making the $t t s$ box almost identical to the consensus sequence.

\section{nopB is expressed in early and late symbiotic stages.}

The expression of conserved genes probably involved in formation of the type III secretion apparatus $(r h c V)$ and of genes encoding secreted proteins ( $g u n A 2$, blr1806, nopL, and nopB) was analyzed in nodules of $M$. atropurpureum using lacZ reporter gene fusions (Table 2). Sections of 4-week-old nodules from $M$. atropurpureum stained with 5-bromo-4-chloro-3-

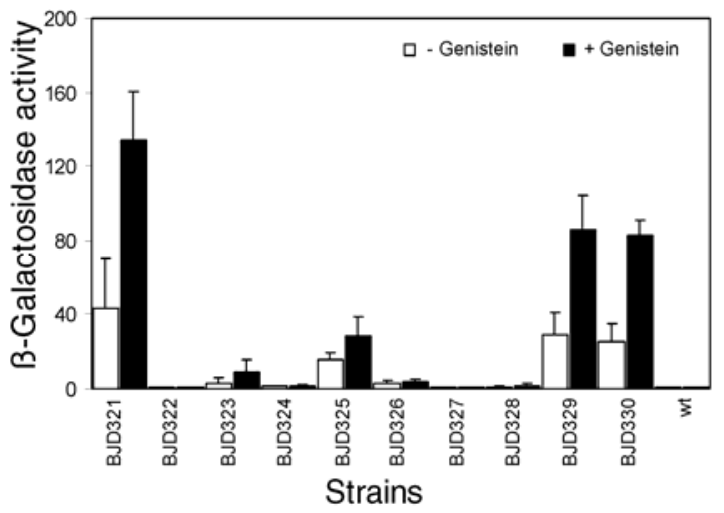

Fig. 3. $\beta$-Galactosidase activity of chromosomally integrated nopB-lac $Z$ fusions with wild-type (BJD321) or modified type-three secretion (tts) box regions. The enzymatic activity was calculated as pmol of 4-methyl umbelliferone formed per minute and cell density (optical density at $600 \mathrm{~nm}$ ). Mean values result from measurements of at least four independent cultures. Standard deviations are indicated. Filled bars $=\beta$-galactosidase activity $24 \mathrm{~h}$ after induction with genistein, Open bars $=\beta$-galactosidase activity without induction, and $\mathrm{wt}=$ wild type without reporter gene.

$$
\begin{aligned}
& \text { tts-box } \\
& \text { CGTCAGGTTTTCGTCAGCTCGGCAGCCLATGAACTTGATCGGTTCAT . . } 38 \text { bp to nopB } \\
& \text { CGTCAGCTTTTCGAAAGCTAAAGCCCCCAGCATGAGCCTGCGAGGTC... } 198 \text { bp to nopL } \\
& \text { CGTCAGCTTCTCGAAAGCCAACCTTCCLAGCATTCAAGCCCGGTCTC... } 91 \text { bp to gunA2 }
\end{aligned}
$$

Fig. 2. Transcriptional start sites determined by 5' rapid amplification of cDNA ends. Transcriptional start sites are marked in bold. Conserved regions of the

\begin{tabular}{|c|c|c|}
\hline Strain & Relevant characteristics $^{\mathbf{a}}$ & Source or reference \\
\hline 110 spc4 & Referred to as wild type, $\mathrm{Sp}^{\mathrm{R}}$ & Regensburger and Hennecke 1983 \\
\hline 1599 & gunA2-lacZ integrated into wild type, $\mathrm{Sp}^{\mathrm{R}} \mathrm{Tc}^{\mathrm{R}}$ & Caldelari Baumberger et al. 2003 \\
\hline wt-179 & $r h c V$-lacZ integrated into wild type, $\mathrm{Sp}^{\mathrm{R}} \mathrm{Tc}^{\mathrm{R}}$ & Krause et al. 2002 \\
\hline$\Delta 139-179$ & $r h c V$-lacZ integrated into the $t t s I$ deletion derivative $\Delta 139, \mathrm{Km}^{\mathrm{R}} \mathrm{Sp}^{\mathrm{R}} \mathrm{Tc}^{\mathrm{R}}$ & Krause et al. 2002 \\
\hline wt-182 & nopL-lac $Z$ integrated into wild type, $\mathrm{Sp}^{\mathrm{R}} \mathrm{Tc}^{\mathrm{R}}$ & Krause et al. 2002 \\
\hline$\Delta 139-182$ & nopL-lac $Z$ integrated into the $t$ tsI deletion derivative $\Delta 139, \mathrm{Km}^{\mathrm{R}} \mathrm{Sp}^{\mathrm{R}} \mathrm{Tc}^{\mathrm{R}}$ & Krause et al. 2002 \\
\hline wt-185 & blr1806-lacZ integrated into wild type, $\mathrm{Sp}^{\mathrm{R}} \mathrm{Tc}^{\mathrm{R}}$ & Krause et al. 2002 \\
\hline$\Delta 139-185$ & blr1806-lacZ integrated into the ttsI deletion derivative $\Delta 139, \mathrm{Km}^{\mathrm{R}} \mathrm{Sp}^{\mathrm{R}} \mathrm{Tc}^{\mathrm{R}}$ & Krause et al. 2002 \\
\hline BJD321 & nopB-lacZ-uidA integrated into wild type, $\mathrm{Sp}^{\mathrm{R}} \mathrm{Tc}^{\mathrm{R}}$ & This work \\
\hline BJD322 & As BJD321, deleted $t t s$ box & This work \\
\hline BJD323 & $\begin{array}{l}\text { As BJD321, deletion of nonconserved CAG between } t \text { ts box region } 2 \text { and 3; additional } \\
\text { substitution of A by C }\end{array}$ & This work \\
\hline BJD324 & As BJD321, deletion of conserved CAG residue in $t t s$ box region 1 & This work \\
\hline BJD325 & As BJD321, insertion of a 3-bp spacer between $t$ ts box region 1 and 2 & This work \\
\hline BJD326 & As BJD321, substitution of TA by AT in tts box region 3 & This work \\
\hline BJD327 & As BJD321, substitution of conserved AG by GA in $t$ ts box region 2 & This work \\
\hline BJD328 & As BJD321, substitution of conserved GT by AC in $t t s$ box region 1 & This work \\
\hline BJD329 & As BJD321, substitution of conserved $\mathrm{C}$ by $\mathrm{A}$ in $t t s$ box region 1 & This work \\
\hline BJD330 & As BJD321, several substitutions to match consensus $t$ ts box & This work \\
\hline
\end{tabular}
type-three secretion (tts) box are underlined. Numbers at the end of the lines indicate distances in base pairs between the transcriptional start site and the assumed translational start site of the corresponding open reading frame.

Table 2. Bradyrhizobium japonicum strains used in this study

${ }^{a} \mathrm{Sp}^{\mathrm{R}}$, spectinomycin resistant; $\mathrm{Tc}^{\mathrm{R}}$, tetracycline resistant; $\mathrm{Km}^{\mathrm{R}}$, kanamycin resistant; and tts = type-three secretion. 
indolyl-3-D-galactoside (X-Gal) are shown in Figure 4A through I. Strong staining was observed for gunA2- and blr1806-lacZ fusion strains (Fig. 4A and G, respectively). Weaker, but clearly visible staining of the infected nodule tissue was observed for $n o p B$-, rhcV-, and nopL-lacZ fusion strains (Fig. 4B, C, and E, respectively). Nodules inoculated with the wild type did not show staining (Fig. 4I).

It was shown previously that induction and function of the T3SS in liquid culture requires the regulator TtsI (Krause et al. 2002; Süß et al. 2006). To test whether this is also the case for expression of $t t s$ genes in nodules, reporter gene fusions of $r h c V$, blr1806, and nopL were integrated in a ttsI mutant background (Table 2). Nodule sections of $M$. atropurpureum infected

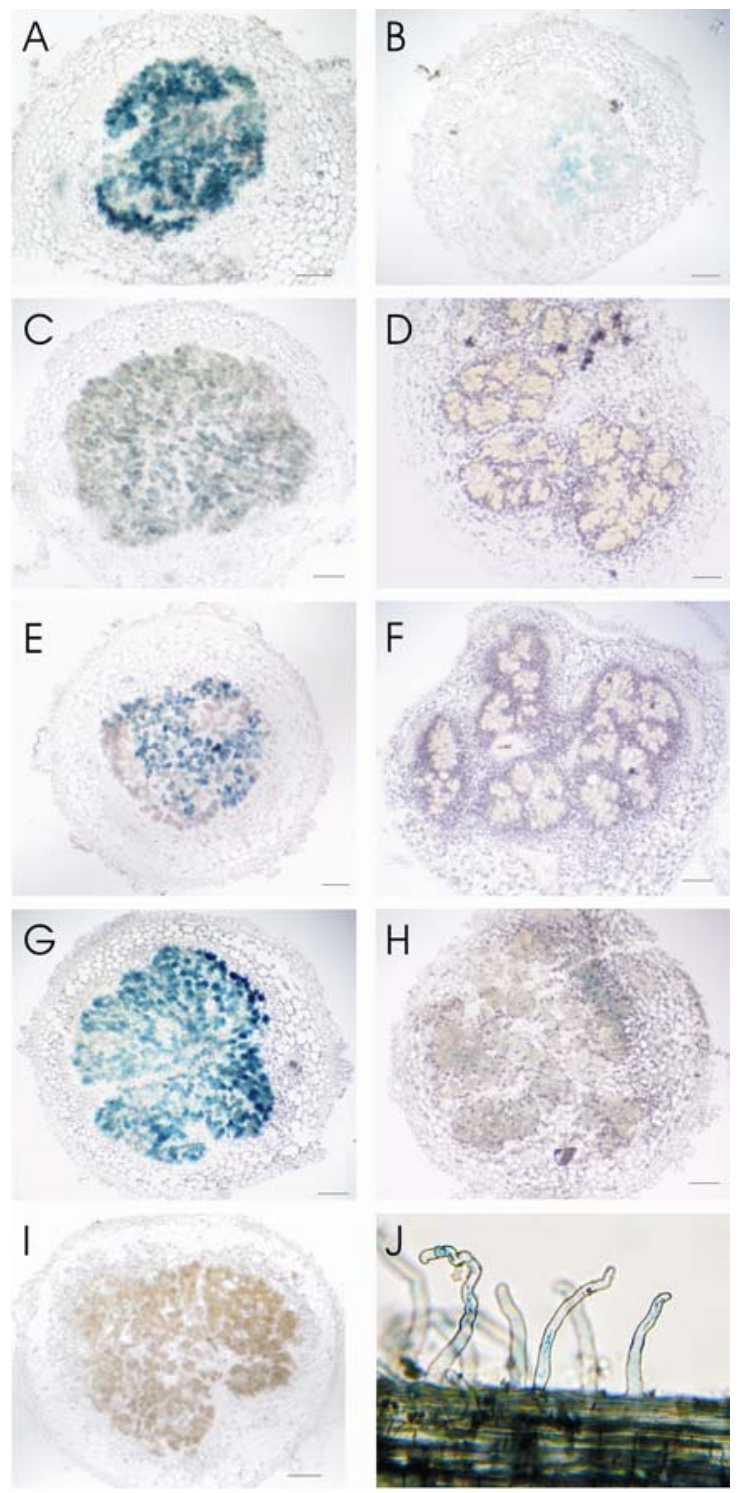

Fig. 4. Expression analysis of type-three secretion (tts) genes in nodules and in the root hair zone of Macroptilium atropurpureum by light microscopy. Plants were infected with strains containing A through $\mathbf{H}$, a lacZ, J, uidA reporter gene fusion, or I, with the wild type. A through I, Staining of cryosections $(25 \mu \mathrm{m}$ thick) of 4 -week-old $M$. atropurpureum nodules was done with 5-bromo-4-chloro-3-indolyl-3-D-galactoside. J, Roots of M. atropurpureum (10 days old) were stained with 5-bromo-4-chloro-3indolyl-3-D-glucuronide. Strains: A, 1599 (gunA2-lacZ); B, BJD321 (nopB-lacZ); C, wt-179 (rhcV-lacZ); D, $\Delta 139-179$ (rhcV-lacZ in ttsI mutant background); E, wt-182 (nopL-lacZ); F, $\Delta 139-182$ (nopL-lacZ in ttsI mutant background); G, wt-185 (blr1806-lacZ); H, $\Delta 139-185$ (blr1806lacZ in ttsI mutant background); I, wild type. Scale bars: $200 \mu \mathrm{m}$. J, Root hairs of M. atropurpureum, inoculated with BJD321 (nopB-uidA). with corresponding mutants showed no $\beta$-galactosidase activity (Fig. 4D and F), with the exception of strain $\Delta 139-185$ (blrl806lacZ), which gave very weak staining after $6 \mathrm{~h}$ (Fig. $4 \mathrm{H})$.

To monitor the expression of nopB during the infection process, roots of 10-day-old plants of $M$. atropurpureum, inoculated with BJD321, were stained with 5-bromo-4-chloro-3indolyl-3-D-glucuronide (X-Gluc). Attachment of B. japonicum and blue staining due to $\beta$-glucuronidase activity was visible in the infection zone, indicating that nopB is active early in infection (Fig. 4J).

\section{DISCUSSION}

The tts box motif was first identified in rhizobial gene regions encoding a T3SS (Krause et al. 2002). Compared with Mesorhizobium loti MAFF303099, where we identified 7 tts box sequences (data not shown), and NGR234, which harbors $11 \mathrm{tts}$ box-like elements on the symbiotic plasmid (Marie et al. 2004), B. japonicum contains a considerably higher number $(n=$ 39) of this motif. In B. japonicum, as in the other strains, the tts box is mainly associated with genes encoding the type III secretion machinery or secreted proteins (Süß et al. 2006). However, several of the motifs described here either are upstream of genes without similarity to known genes or no genes have been annotated downstream. Therefore, the possibility exists that these motifs are associated with genes not involved in type III secretion. In NGR234, the $t$ ts box was also found upstream of genes involved in rhamnan biosynthesis and plasmid stability (Marie et al. 2004).

We found that most regions downstream of $t$ ts boxes were expressed. This is corroborated by microarray data that indicate weak expression of genes downstream of $32 \mathrm{tts}$ boxes (Lang et al. 2008) (GEO accession GSE8580). The transcription start sites of nopL, nopB and gunA2 were determined by 5' RACE and found to be located 11, 12, and $10 \mathrm{bp}$ downstream of the $t t s$ box, respectively. Previously, the transcription start sites of $n o p B$ and $n o p X$ (formerly nolB and $n o l X$ ) of $S$. fredii were determined (Kovacs et al. 1995). Analysis of the upstream region of these genes revealed the presence of $t$ ts box motifs at a distance of 10 and 11 bp (Kovacs et al. 1995; Krause et al. 2002). Therefore, the $t t s$ box seems to be located in the transcriptional control region of these genes and its tripartite structure could represent a new promoter type. This is supported by results obtained here with modified $t t s$ box motifs upstream of a nopB-lacZ fusion. A deletion of the tts box reduced $\beta$-galactosidase activity to background level (strain BJD322). The modification of two or more nucleotides in any of the conserved three regions also affected reporter activity significantly. In NGR234, an exchange of 3 nucleotides in region 1 (GTCAG to GAATC) results in a loss of function of the $t t s$ box in vivo (Wassem et al. 2008).

Because none of the modifications led to an increased $\beta$-galactosidase activity, we exclude the possibility that the $t$ ts box is a repressor-binding site. The localization of the $t t s$ box in close vicinity to the transcription start suggests that the RNA polymerase holoenzyme interacts with at least part of the motif. It is not known if the "housekeeping" sigma factor SigA recognizes the $t$ ts box. For B. japonicum, it was shown that SigA recognizes a $-35 /-10$ motif (TTGACA-N ${ }_{17}$-TATAAC), which is more similar to the consensus sequence of Escherichia coli (Beck et al. 1997). MacLellan and associates (2006) described a similar motif (CTTGAC-N $\mathrm{N}_{17}$-CTATAT) for $S$. meliloti. The $t$ ts box also has no similarity to the $-24 /-12$ promoter motif recognized by RpoN (Fischer 1994). Therefore, the tts box might be the recognition site for one of the uncharacterized sigma factors encoded in the B. japonicum genome (Kaneko et al. 2002). However, by comparison of the putative sigma factors of $B$. japonicum with 
those of M. loti MAFF303099 (Kaneko et al. 2000), which also contains the highly conserved $t$ ts box motif, no obvious candidate arises. To date, TtsI, which is conserved in all rhizobial strains that contain tts box motifs, is the only known regulator likely to interact with the upstream regions of genes preceded by a $t$ ts box. The gene is essential for the genistein-dependent activation of the T3SS in liquid culture (Krause et al. 2002; Süß et al. 2006) and required for expression in planta, as we showed in this study. Electromobility shift assays using purified TtsI protein confirmed the binding of the regulator to a tts box-containing fragment (Wassem et al. 2008).

Although it has been shown that the T3SS of rhizobia affects symbiosis, little is known about its expression in the rhizosphere and during nodule development. Krause and associates (2002) showed the induction of $t$ ts genes by genistein in liquid cultures. Herein we showed that a transcriptional nopBuidA fusion is expressed early in infection of Macroptilium atropurpureum. NopX (formerly NolX), a type III-secreted protein of $S$. fredii, was localized by immunocytochemical studies in infection threads of soybean and cowpea but not in mature nodules (Krishnan 2002). In a proteome analysis-based approach, proteins from bacteroids of $B$. japonicum isolated from 4 -week-old soybean nodules were analyzed. No proteins known to be involved in type III secretion were reported (Sarma and Emerich 2005). With NGR234, transcripts were detected in mature nodules of different host plants (e.g., for nopB and $r h c N$ ) but not for $r h c V$, $r h c C l$, and most of the other genes belonging to the $t$ ts cluster (Perret et al. 1999). Recently, Chang and associates (2007) reported a strong repression of $t t s$ genes in B. japonicum bacteroids 4 weeks after inoculation of soybean compared with free-living cells grown in rich medium. They suggest that the T3SS is required only during nodule initiation. A more detailed transcriptome analysis revealed that $t t s$ genes are maximally expressed in bacteroids 10 and 13 days after inoculation of soybean seedlings, and expression decreases in nodules 21 and 31 days after inoculation (Pessi et al. 2007) (GEO accession GSE8478). We found that genes coding for the T3SS are well expressed in mature nodules of $M$. atropurpureum, especially genes encoding secreted proteins (gunA2 and blr1806). Although the T3SS is expressed in both host plants, it affects nodule number and development with $M$. atropurpureum much more strongly than with soybean (Krause et al. 2002). This indicates that the two host plants might respond differently to effector proteins. For NGR234, it was reported that secreted proteins have a host-specific effect on symbiosis (Skorpil et al. 2005).

We conclude that genes of the T3SS are active in early infection stages and in mature nodules of $M$. atropurpureum. Therefore, it is likely that the secretion of effector proteins influences symbiosis with $M$. atropurpureum at all stages.

\section{MATERIALS AND METHODS}

\section{Strains and growth conditions.}

B. japonicum strains used in this study are listed in Table 2 . For conjugation and plant assays, B. japonicum was grown in peptone salts yeast extract medium (Regensburger and Hennecke 1983). Cultures were harvested by centrifugation, the supernatant was removed, and the cell pellet was washed twice in $0.9 \% \mathrm{NaCl}$ solution. The cells were suspended in $0.9 \% \mathrm{NaCl}$ and used for plant inoculation or conjugation. For 5' RACE and $\beta$-galactosidase assays, a single colony of $B$. japonicum was inoculated in AG medium (Sadowsky et al. 1987) containing spectinomycin $(100 \mu \mathrm{g} / \mathrm{ml})$ and incubated for 3 days at $28^{\circ} \mathrm{C}$. From this preculture, AG medium was inoculated 1:100 and genistein was added to a final concentration of $1 \mu \mathrm{M}$.
Determination of transcriptional start sites by $5^{\prime}$ RACE.

B. japonicum cells were harvested $24 \mathrm{~h}$ after induction with genistein. Primers used for 5' RACE (Frohman et al. 1988) are listed in Table 3. Total RNA isolation was performed as described (Hauser et al. 2007). cDNA was synthesized at $45^{\circ} \mathrm{C}$ for $50 \mathrm{~min}$ with Superscript II (Invitrogen, Carlsbad, CA, U.S.A.) using gene-specific primers (Table 3). The cDNA was treated with RNase $\mathrm{H}\left(20 \mathrm{~min}, 37^{\circ} \mathrm{C}\right)$ and subsequently purified with a microcon YM-30 filter (Millipore, Schwalbach, Germany). The cDNA solution was treated with alkaline phosphatase $\left(10 \mathrm{~min}\right.$ at $37^{\circ} \mathrm{C}$ and $10 \mathrm{~min}$ at $\left.65^{\circ} \mathrm{C}\right)$ to avoid incorporation of dNTPs in the subsequent tailing reaction. A deoxynucleotide tail was added to the $3^{\prime}$ end of the cDNA using terminal transferase (5 U). For nopB and gunA2, a dA tail was generated; in the case of nopL, a dT tail was synthesized. Second-strand synthesis was performed with an oligo (dT) primer for nopB and gunA2 and with an oligo (dA) primer for nopL. The obtained double-stranded DNA was amplified with the anchor-1 primer and a second gene-specific primer (Table 3 ). The resulting PCR product was eluted from an agarose gel and cloned into pCR2.1 by TA cloning (Invitrogen). The transcriptional start site was determined by sequencing.

\section{Reverse-transcription PCR \\ for regions downstream of $\boldsymbol{t t s}$ boxes.}

B. japonicum was inoculated in AG medium from a preculture to an optical density at $600 \mathrm{~nm}\left(\mathrm{OD}_{600}\right)$ of 0.4 . Genistein was added to a final concentration of $1 \mu \mathrm{M}$ and cells were grown for $8 \mathrm{~h}$. Then, $40 \mathrm{ml}$ of genistein-induced cultures were transferred into centrifuge tubes containing $4 \mathrm{ml}$ of stopsolution ( $10 \%$ water-saturated phenol in ethanol, prechilled at $-20^{\circ} \mathrm{C}$ ) and mixed by inversion. After centrifugation for $4 \mathrm{~min}$ $\left(5,445 \times g, 4^{\circ} \mathrm{C}\right)$, the supernatant was discarded and the pellet was frozen in liquid nitrogen. Total RNA was isolated as described (Hauser et al. 2007). RNA was checked by PCR for complete removal of DNA contamination by using primers that amplify a 108-bp fragment of nolZ. cDNA synthesis was performed with $10 \mu \mathrm{g}$ of DNA-free RNA, $750 \mathrm{ng}$ of random hexamer primers, $30 \mathrm{U}$ of SUPERaseIn (Ambion, Huntingdon, U.K.), and 1,500 U of M-MLV reverse transcriptase (Promega, Mannheim, Germany) in supplied reaction buffer. The reaction mixture was incubated at $37^{\circ} \mathrm{C}$ for $60 \mathrm{~min}$ and at $42^{\circ} \mathrm{C}$ for a further $60 \mathrm{~min}$. M-MLV reverse transcriptase was inactivated by heat $\left(70^{\circ} \mathrm{C}, 10 \mathrm{~min}\right)$ and RNA was hydrolyzed by alkaline treatment $\left(0.2 \mathrm{M} \mathrm{NaOH}, 65^{\circ} \mathrm{C}, 30 \mathrm{~min}\right)$. The cDNA solution was adjusted to neutral $\mathrm{pH}$ with $1 \mathrm{M} \mathrm{HCl}$, and cDNA was subsequently purified with a MinElute PCR purification kit (Qiagen, Hilden, Germany). PCR amplification was performed using 5 to $10 \mathrm{ng}$ of cDNA and primers that bind 20 to $200 \mathrm{bp}$ downstream of the tts boxes (a list of the primers is available on request). The selected product length was 80 to $120 \mathrm{bp}$. Product formation was confirmed by agarose gel electrophore-

Table 3. Oligonucleotides used for $5^{\prime}$ rapid amplification of cDNA ends

\begin{tabular}{ll}
\hline Primer & \multicolumn{1}{c}{$\mathbf{5}^{\prime} \rightarrow \mathbf{3}^{\prime}$ Sequence $^{\mathbf{a}}$} \\
\hline nopL-SP1 $^{\text {b }}$ & GTCGAGATAGGGTGAATAAGCCTC \\
gunA2-SP1 $^{\text {b }}$ & TCGTTGTTCCAAGAGTAGCCAT \\
nopB-SP1 $^{\text {b }}$ & CACCCCATTTACGACAGCC \\
dA-anchor-1 & AACTGTGTAAGCTTAGGTACG(A) ${ }_{17}$ B \\
dT-anchor-1 & AACTGTGTAAGCTTAGGTACG(T) ${ }_{17} \mathrm{~V}$ \\
nopL-SP2 $^{c}$ & TAAGCCTCGCCCTGCAGCACTGGATGG \\
gunA2-SP2 & ATCGCGTGAAAAGCTTCCGTATGGAGCG \\
nopB-SP2 & GATACTGCAGCGGAGAAACGGCTCGACCCTG \\
anchor-1 & ACTGTGTAAGCTTAGGTACG
\end{tabular}

\footnotetext{
${ }^{a}$ Nucleotide abbreviations: B meaning C, G or T; V meaning A, C or G.

${ }^{\mathrm{b}}$ Gene-specific primer used for first strand cDNA synthesis.

${ }^{c}$ Gene-specific primer used for polymerase chain reaction.
} 
sis. If no PCR fragment was obtained, a different pair of primers annealing further downstream was used.

\section{Construction and chromosomal integration of translational nopB-lac $Z$ and transcriptional nopB-uidA fusions.}

For fusions of nopB with the reporter genes lacZ and uidA, plasmid pSUP81-ZA was used. The plasmid was constructed by cloning the promoter-less uidA gene of pWM3 (Metcalf and Wanner 1993) and the lacZ gene of pNM481 (Minton 1984) in pSUPPOL2SCA (Krause et al. 2002). The sequence of this plasmid has been deposited under accession number EU294195. Approximately $500 \mathrm{bp}$ of the upstream region of $n o p B$ was amplified by PCR and cloned into PacI and StuI sites of pSUP81-ZA. By this, the promoter and the translational start codon of $n o p B$ were fused to $l a c Z$ and a transcriptional fusion with the downstream located uidA was created. The fusion site with $l a c Z$ was confirmed by DNA sequencing. The resulting plasmid pBJD321 was transferred to B. japonicum by biparental conjugation as described previously (Krause et al. 2002). The plasmid integrated into the chromosome by homologous recombination generating strain BJD321. The correct integration event was confirmed by sequencing. For mutagenesis, the $t t s$ box-containing region upstream of nopB was amplified by overlap extension PCR using modified primers. These fragments were cloned into pSUP81-ZA, resulting in plasmids pBJD322 to pBJD330. The plasmids were conjugated and integrated into B. japonicum, resulting in strains BJD321 to BJD330 (Tables 1 and 2). The modified and chromosomally inserted fragments were confirmed by sequencing.

\section{Determination of $\beta$-galactosidase activity.}

Cells were induced with genistein for $24 \mathrm{~h}$ and collected by centrifugation $\left(4,000 \times g, 4^{\circ} \mathrm{C}\right)$. The cell pellet was resuspended in $10 \mathrm{ml}$ of $0.9 \% \mathrm{NaCl}$. The cell density was measured at 600 $\mathrm{nm}$. Samples of 4 by $2 \mathrm{ml}$ were centrifuged $(4,000 \times g, 10$ $\min )$, the supernatant was removed, and the cells were frozen in liquid nitrogen. $\beta$-Galactosidase activity was determined as described previously using 4-methylumbelliferyl- $\beta$-D-galactopyranoside as substrate (Krause et al. 2002). Fluorescence of the reaction product 4-methyl umbelliferone (MU) was measured in a 96-well plate in a fluorometer Infinite 200 (Tecan, Crailsheim, Germany) by excitation at $360 \mathrm{~nm}$ and by emission at $460 \mathrm{~nm}$. $\beta$-Galactosidase activity was calculated as pmol 4MU formed per minute reaction time and cell density $\left(\mathrm{OD}_{600}\right)$.

\section{Staining of nodule sections and root hairs.}

M. atropurpureum cv. Aztec atro seed were surface sterilized and germinated on $1 \%$ water agar at $30^{\circ} \mathrm{C}$ for 2 to 3 days. Germinated seed were inoculated and grown as described previously (Krause et al. 2002). Root nodules were harvested 28 days after inoculation. Histological staining was done with minor modifications as described (Teeri et al. 1989). Nodules were fixed with $1.25 \%$ glutaraldehyde in $Z^{\prime}$ buffer $(60 \mathrm{mM}$ $\mathrm{Na}_{2} \mathrm{HPO}_{4}, 40 \mathrm{mM} \mathrm{NaH} \mathrm{PO}_{4}, 10 \mathrm{mM} \mathrm{KCl}, 1 \mathrm{mM} \mathrm{MgSO}$, pH 7) for $2 \mathrm{~h}$ at room temperature in vacuum and then rinsed twice with $\mathrm{Z}^{\prime}$ buffer ( $\left.\mathrm{pH} 7.2,15 \mathrm{~min}\right)$. The fixed nodules were embedded in Leica OCT Cryocompound (Leica Microsystems, Wetzlar, Germany), frozen at $-20^{\circ} \mathrm{C}$, and sectioned. Sections approximately $25 \mu \mathrm{m}$ thick were rehydrated with distilled water and stained with the substrate $\mathrm{X}-\mathrm{Gal}$ by incubation in staining solution $\left(5 \mathrm{mM} \mathrm{K}_{3} \mathrm{Fe}(\mathrm{CN})_{6}, 5 \mathrm{mM} \mathrm{K}_{4} \mathrm{Fe}(\mathrm{CN})_{6}\right.$, and $0.2 \% \mathrm{X}$-Gal in $\mathrm{Z}^{\prime}$ buffer) at $28^{\circ} \mathrm{C}$ for 2 to $4 \mathrm{~h}$. Sections were analyzed by bright-field microscopy.

Root hairs were stained with X-Gluc 10 days after germination. For this, plant roots were washed and submerged in staining solution (X-Gluc at $200 \mu \mathrm{g} / \mathrm{ml} ; 0.1 \mathrm{M}$ sodium phosphate buffer, pH 7; $0.5 \mathrm{mM} \mathrm{K}{ }_{3} \mathrm{Fe}(\mathrm{CN})_{6} ; 0.5 \mathrm{mM} \mathrm{K}_{4} \mathrm{Fe}(\mathrm{CN})_{6}$, and $0.3 \%$ Triton $\mathrm{X}-100)$, subjected to vacuum for $15 \mathrm{~min}$, and incubated overnight at $28^{\circ} \mathrm{C}$. Roots were observed by brightfield microscopy.

\section{ACKNOWLEDGMENTS}

We thank H.-M. Fischer for the strain B. japonicum 1599 (gunA2-lacZ) and M. Kallmeyer and M. Weishaupt for technical assistance.

\section{LITERATURE CITED}

Bartsev, A. V., Boukli, N. M., Deakin, W. J., Staehelin, C., and Broughton, W. J. 2003. Purification and phosphorylation of the effector protein NopL from Rhizobium sp. NGR234. FEBS (Fed. Eur. Biochem. Soc.) Lett. 554:271-274.

Beck, C., Marty, R., Kläusli, S., Hennecke, H., and Göttfert, M. 1997. Dissection of the transcription machinery for housekeeping genes of Bradyrhizobium japonicum. J. Bacteriol. 179:364-369.

Broughton, W. J., Jabbouri, S., and Perret, X. 2000. Keys to symbiotic harmony. J. Bacteriol. 182:5641-5652.

Caldelari Baumberger, I., Fraefel, N., Göttfert, M., and Hennecke, H. 2003. New NodW- or NifA-regulated Bradyrhizobium japonicum genes. Mol. Plant-Microbe Interact. 16:342-351.

Chang, W. S., Franck, W. L., Cytryn, E., Jeong, S., Joshi, T., Emerich, D. W., Sadowsky, M. J., Xu, D., and Stacey, G. 2007. An oligonucleotide microarray resource for transcriptional profiling of Bradyrhizobium japonicum. Mol. Plant-Microbe Interact. 20:1298-1307.

Fischer, H.-M. 1994. Genetic regulation of nitrogen fixation in rhizobia. Microbiol. Rev. 58:352-386.

Frohman, M. A., Dush, M. K., and Martin, G. R. 1988. Rapid production of full-length cDNAs from rare transcripts: amplification using a single gene-specific oligonucleotide primer. Proc. Natl. Acad. Sci. U.S.A. 85:8998-9002.

Göttfert, M., Röthlisberger, S., Kündig, C., Beck, C., Marty, R., and Hennecke, H. 2001. Potential symbiosis-specific genes uncovered by sequencing a 410-kilobase DNA region of the Bradyrhizobium japonicum chromosome. J. Bacteriol. 183:1405-1412.

Hauser, F., Pessi, G., Friberg, M., Weber, C., Rusca, N., Lindemann, A., Fischer, H.-M., and Hennecke, H. 2007. Dissection of the Bradyrhizobium japonicum NifA $+\sigma^{54}$ regulon, and identification of a ferredoxin gene $(f d x N)$ for symbiotic nitrogen fixation. Mol. Genet. Genomics 278:255-271.

Kaneko, T., Nakamura, Y., Sato, S., Asamizu, E., Kato, T., Sasamoto, S., Watanabe, A., Idesawa, K., Ishikawa, A., Kawashima, K., Kimura, T., Kishida, Y., Kiyokawa, C., Kohara, M., Matsumoto, M., Matsuno, A., Mochizuki, Y., Nakayama, S., Nakazaki, N., Shimpo, S., Sugimoto, M., Takeuchi, C., Yamada, M., and Tabata, S. 2000. Complete genome structure of the nitrogen-fixing symbiotic bacterium Mesorhizobium loti. DNA Res. 7:331-338.

Kaneko, T., Nakamura, Y., Sato, S., Minamisawa, K., Uchiumi, T. Sasamoto, S., Watanabe, A., Idesawa, K., Iriguchi, M., Kawashima, K., Kohara, M., Matsumoto, M., Shimpo, S., Tsuruoka, H., Wada, T. Yamada, M., and Tabata, S. 2002. Complete genomic sequence of nitrogen-fixing symbiotic bacterium Bradyrhizobium japonicum USDA110. DNA Res. 9:189-197.

Kovacs, L. G., Balatti, P. A., Krishnan, H. B., and Pueppke, S. G. 1995. Transcriptional organization and expression of noIXWBTUV, a locus that regulates cultivar-specific nodulation of soybean by Rhizobium fredii USDA257. Mol. Microbiol. 17:923-933.

Krause, A., Doerfel, A., and Göttfert, M. 2002. Mutational and transcriptional analysis of the type III secretion system of Bradyrhizobium ja ponicum. Mol. Plant-Microbe Interact. 15:1228-1235.

Krishnan, H. B. 2002. NolX of Sinorhizobium fredii USDA257, a type IIIsecreted protein involved in host range determination, is localized in the infection threads of cowpea (Vigna unguiculata [L.] Walp) and soybean (Glycine max [L.] Merr.) nodules. J. Bacteriol. 184:831-839.

Krishnan, H. B., Lorio, J., Kim, W. S., Jiang, G., Kim, K. Y., DeBoer, M., and Pueppke, S. G. 2003. Extracellular proteins involved in soybean cultivar-specific nodulation are associated with pilus-like surface appendages and exported by a type III protein secretion system in Sinorhizobium fredii USDA257. Mol. Plant-Microbe Interact. 16:617-625.

Lang, K., Lindemann, A., Hauser, F., and Göttfert, M. 2008. The genistein stimulon of Bradyrhizobium japonicum. Mol. Genet. Genomics 279:203-211

Long, S. R. 2001. Genes and signals in the Rhizobium-legume symbiosis. Plant Physiol. 125:69-72.

Lorio, J. C., Kim, W. S., and Krishnan, H. B. 2004. NopB, a soybean culti- 
var-specificity protein from Sinorhizobium fredii USDA257, is a type III secreted protein. Mol. Plant-Microbe Interact. 17:1259-1268.

MacLellan, S. R., MacLean, A. M., and Finan, T. M. 2006. Promoter prediction in the rhizobia. Microbiology 152:1751-1763.

Marie, C., Broughton, W. J., and Deakin, W. J. 2001. Rhizobium type III secretion systems: legume charmers or alarmers? Curr. Opin. Plant Biol. 4:336-342.

Marie, C., Deakin, W. J., Viprey, V., Kopcinska, J., Golinowski, W., Krishnan, H. B., Perret, X., and Broughton, W. J. 2003. Characterization of Nops, nodulation outer proteins, secreted via the type III secretion system of NGR234. Mol. Plant-Microbe Interact. 16:743-751.

Marie, C., Deakin, W. J., Ojanen-Reuhs, T., Diallo, E., Reuhs, B., Broughton, W. J., and Perret, X. 2004. TtsI, a key regulator of Rhizobium species NGR234 is required for type III-dependent protein secretion and synthesis of rhamnose-rich polysaccharides. Mol. PlantMicrobe Interact. 17:958-966.

Metcalf, W. W., and Wanner, B. L. 1993. Construction of new $\beta$-glucuronidase cassettes for making transcriptional fusions and their use with new methods for allele replacement. Gene 129:17-25.

Minton, N. P. 1984. Improved plasmid vectors for the isolation of translational lac gene fusions. Gene 31:269-273.

Perret, X., Freiberg, C., Rosenthal, A., Broughton, W. J., and Fellay, R. 1999. High-resolution transcriptional analysis of the symbiotic plasmid of Rhizobium sp. NGR234. Mol. Microbiol. 32:415-425

Pessi, G., Ahrens, C. H., Rehrauer, H., Lindemann, A., Hauser, F., Fischer, H.-M., and Hennecke, H. 2007. Genome-wide transcript analysis of Bradyrhizobium japonicum bacteroids in soybean root nodules. Mol. Plant-Microbe Interact. 20:1353-1363.

Regensburger, B., and Hennecke, H. 1983. RNA polymerase from Rhizobium japonicum. Arch. Microbiol. 135:103-109.

Saad, M. M., Kobayashi, H., Marie, C., Brown, I. R., Mansfield, J. W.,
Broughton, W. J., and Deakin, W. J. 2005. NopB, a type III secreted protein of Rhizobium sp. strain NGR234, is associated with pilus-like surface appendages. J. Bacteriol. 187:1173-1181.

Sadowsky, M. J., Tully, R. E., Cregan, P. B., and Keyser, H. H. 1987. Genetic diversity in Bradyrhizobium japonicum serogroup 123 and its relation to genotype-specific nodulation of soybean. Appl. Environ. Microbiol. 53:2624-2630.

Sarma, A. D., and Emerich, D. W. 2005. Global protein expression pattern of Bradyrhizobium japonicum bacteroids: a prelude to functional proteomics, Proteomics 5:4170-4184.

Skorpil, P., Saad, M. M., Boukli, N. M., Kobayashi, H., Ares-Orpel, F., Broughton, W. J., and Deakin, W. J. 2005. NopP, a phosphorylated effector of Rhizobium sp. strain NGR234, is a major determinant of nodulation of the tropical legumes Flemingia congesta and Tephrosia vogelii. Mol. Microbiol. 57:1304-1317.

Spaink, H. P. 2000. Root nodulation and infection factors produced by rhizobial bacteria. Annu. Rev. Microbiol. 54:257-288.

Süß, C., Hempel, J., Zehner, S., Krause, A., Patschkowski, T., and Göttfert, M. 2006. Identification of genistein-inducible and type III-secreted proteins of Bradyrhizobium japonicum. J. Biotechnol. 126:69-77.

Teeri, T. H., Lehvaslaiho, H., Franck, M., Uotila, J., Heino, P., Palva, E. T. Van Montagu, M., and Herrera-Estrella, L. 1989. Gene fusions to lacZ reveal new expression patterns of chimeric genes in transgenic plants. EMBO (Eur. Mol. Biol. Organ.) J. 8:343-350.

Viprey, V., Del Greco, A., Golinowski, W., Broughton, W. J., and Perret, X. 1998. Symbiotic implications of type III protein secretion machinery in Rhizobium. Mol. Microbiol. 28:1381-1389.

Wassem, R., Kobayashi, H., Kambara, K., Le Quéré, A., Walker, G. C. Broughton, W. J., and Deakin, W. J. 2008. TtsI regulates symbiotic genes in Rhizobium species NGR234 by binding to tts boxes. Mol. Microbiol. 68:736-748. 